\title{
Parent material and organic matter control soil microbial processes in African tropical rainforests
}
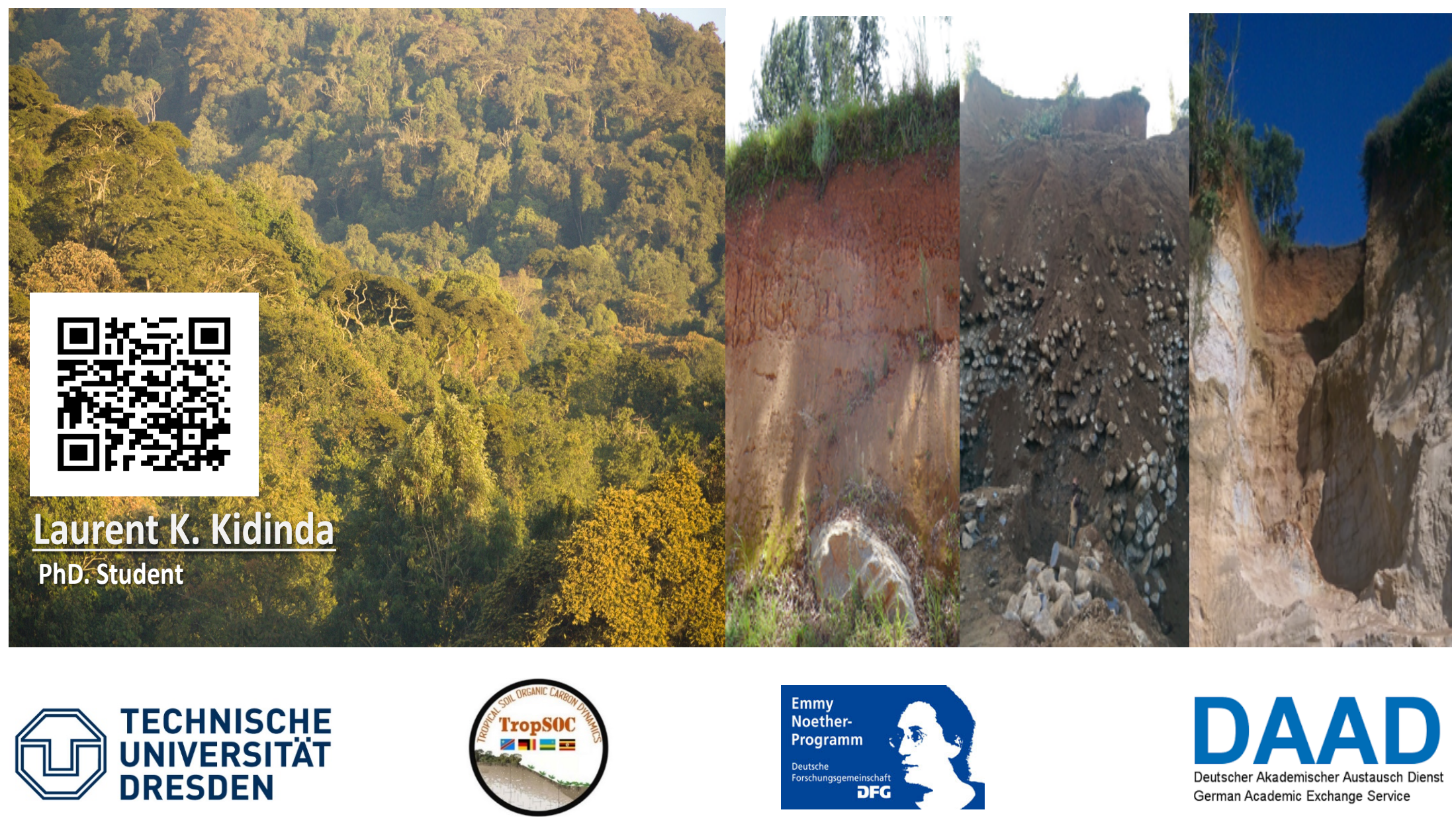

Special thanks go to my supervisors: Prof. Dr. Karsten Kalbitz, Dr. Cordula Vogel, and Prof. Dr. Sebastian Doetterl 


\section{Why is it important to understand the patterns of microbial processes and their controls?}

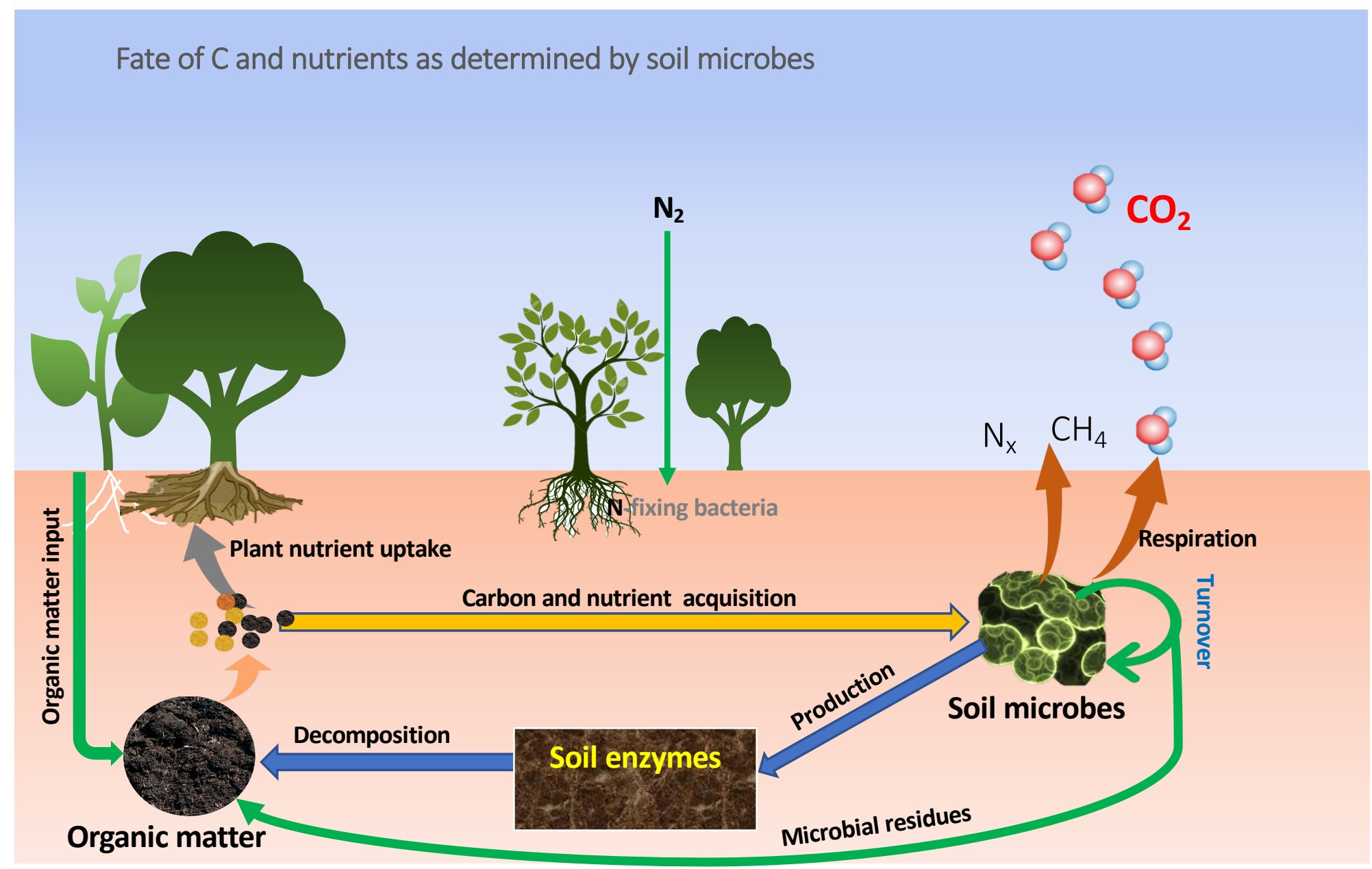


What do we know about the patterns of microbial processes in temperate vs. tropical soils?

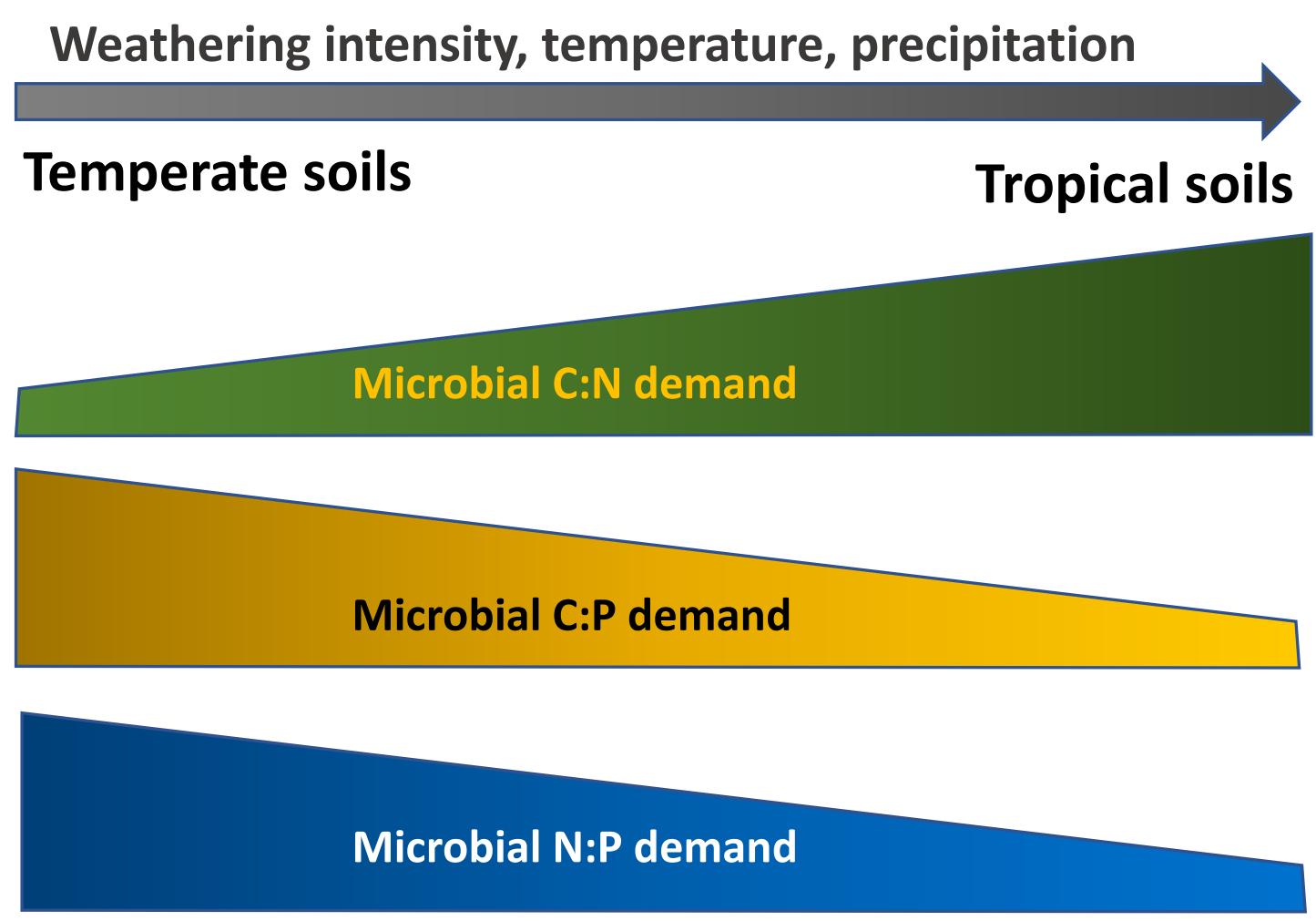

Xu et al., 2013; Liu et al., 2020; Jing et al., 2020 


\section{Microbial processes in tropical Africa still largely understudied...}

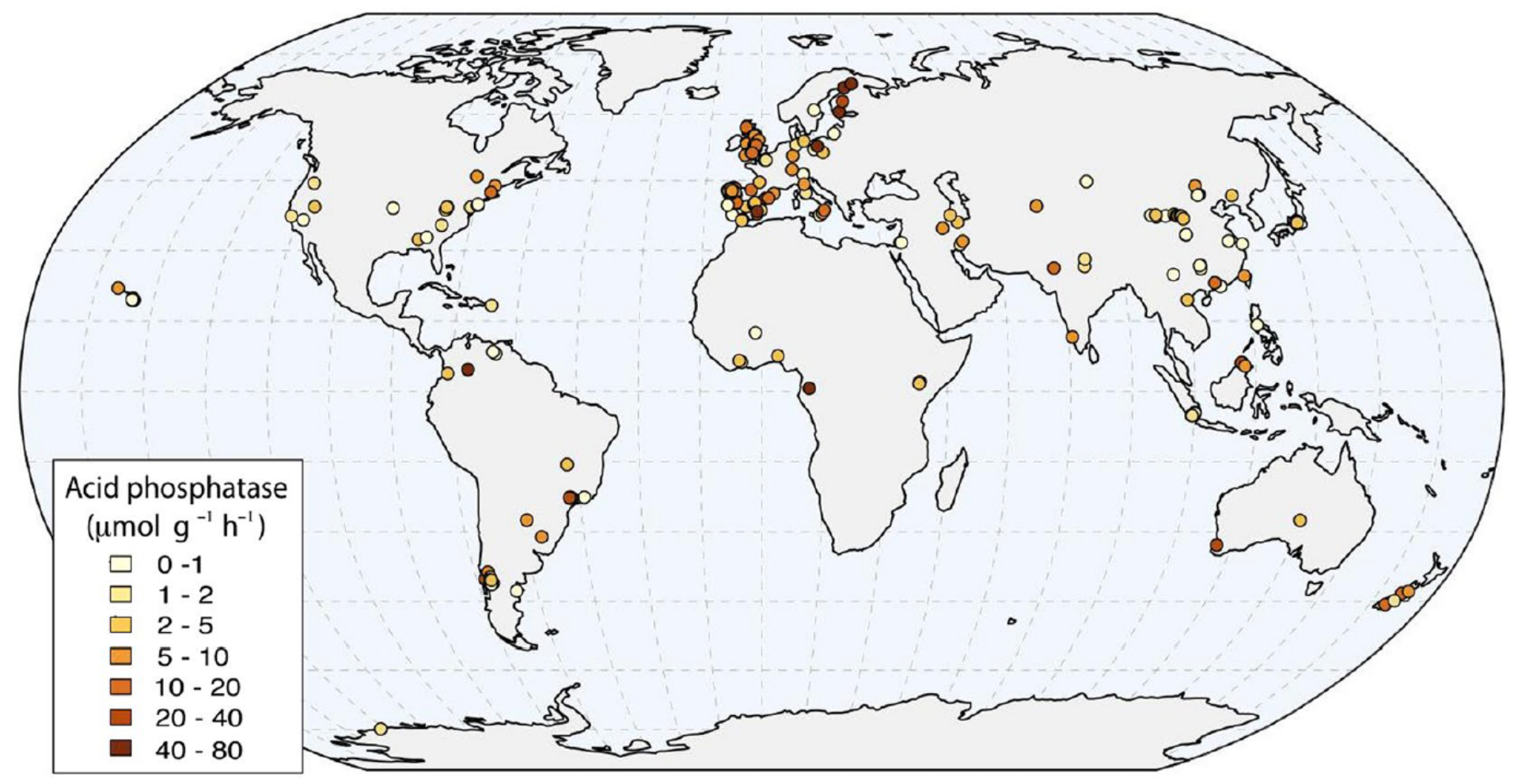

Margalef et al., 2017 
Why can't we just transfer findings from other tropical regions to tropical Africa?

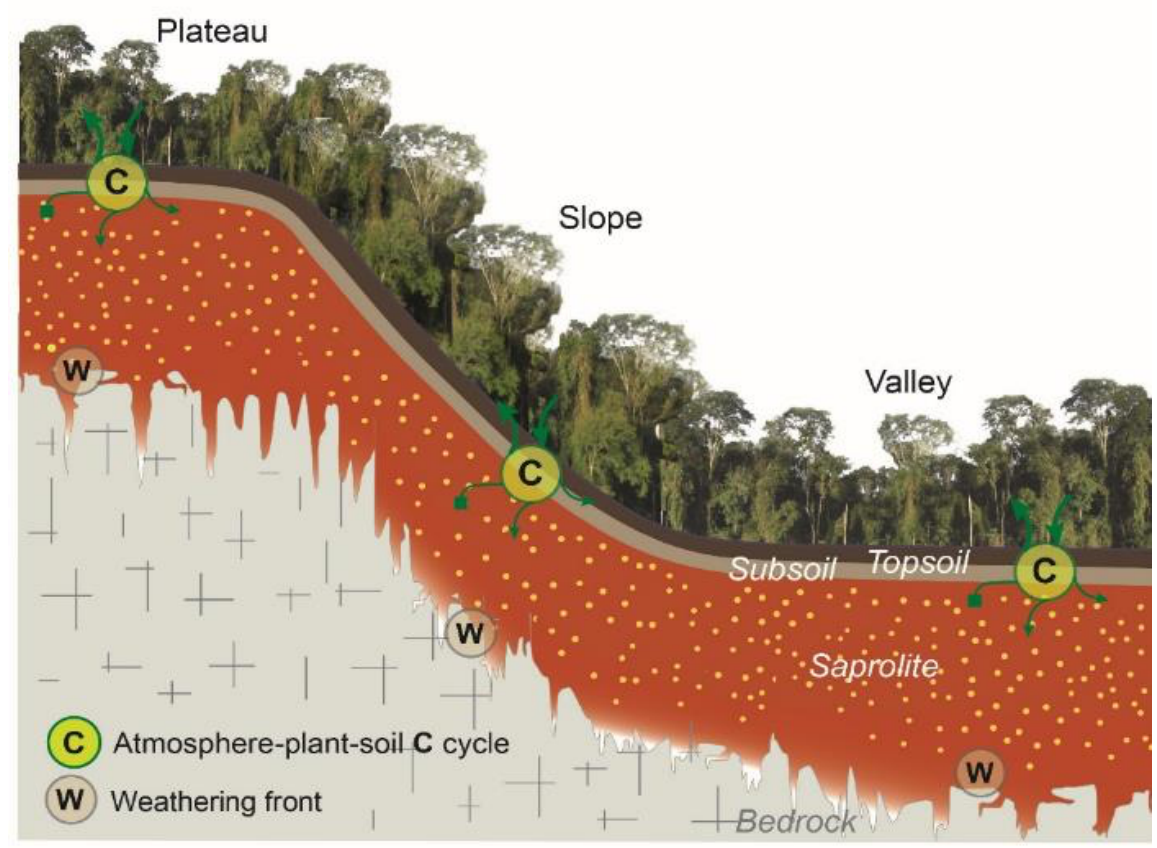

There is a diversity of physico-chemical properties that reflect the heterogeneity of parent materials

Doetterl et al., 2016

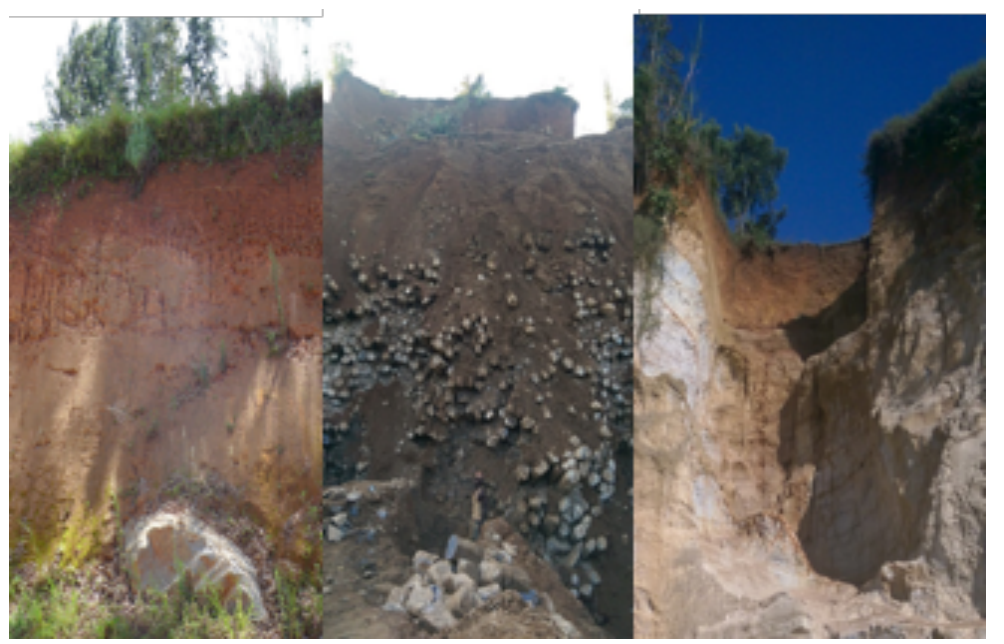




\section{Research questions}

- Do patterns of microbial processes in deeply weathered tropical soils still reflect the geochemical gradient of parent material under similar climatic conditions?

- Are microbes in subsoil in highly weathered tropical forest soils more Cand nutrient-limited than their topsoil counterparts?

- What are important controls on soil microbial biomass, $\mathrm{C}$ and nutrient limitation? 


\section{Sample collection and soil analysis}

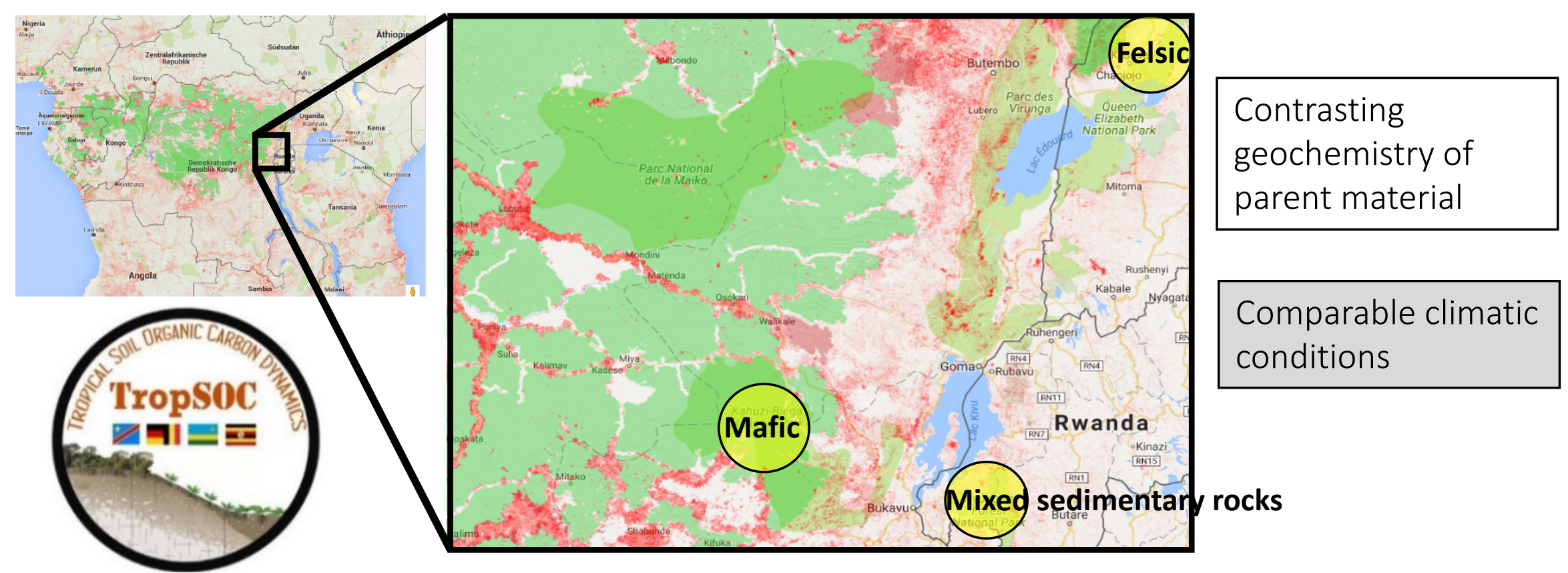

Soil depths

$0-10 \mathrm{~cm}$

$30-40 \mathrm{~cm}$

A 120-day incubation experiment

$60-70 \mathrm{~cm}$ 


\section{Patterns of microbial biomass along geochemical gradient}

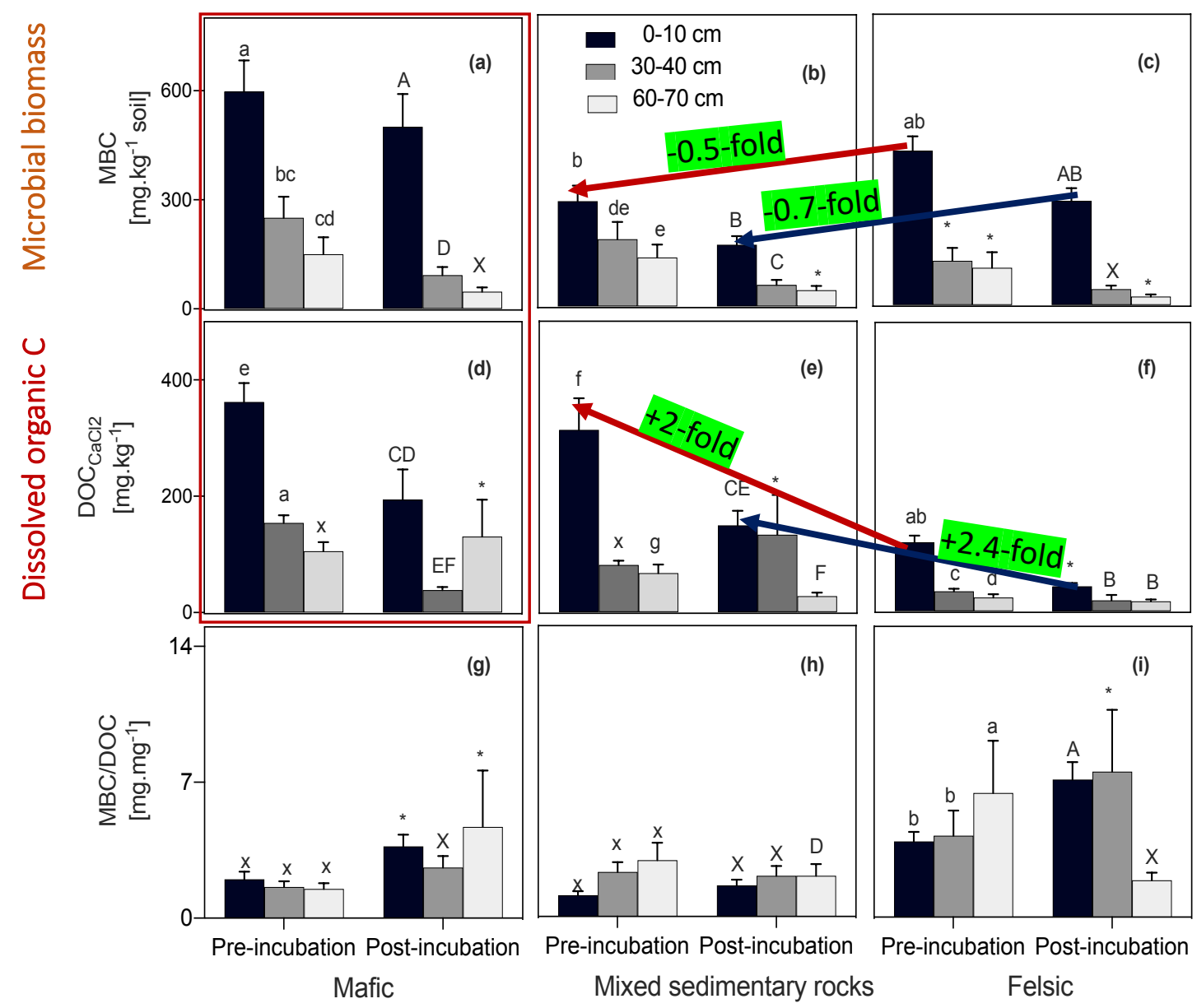

Mafic region has the highest DOC and microbial biomass

Higher DOC in the sedimentary rock than in felsic region did not lead to higher microbial biomass 

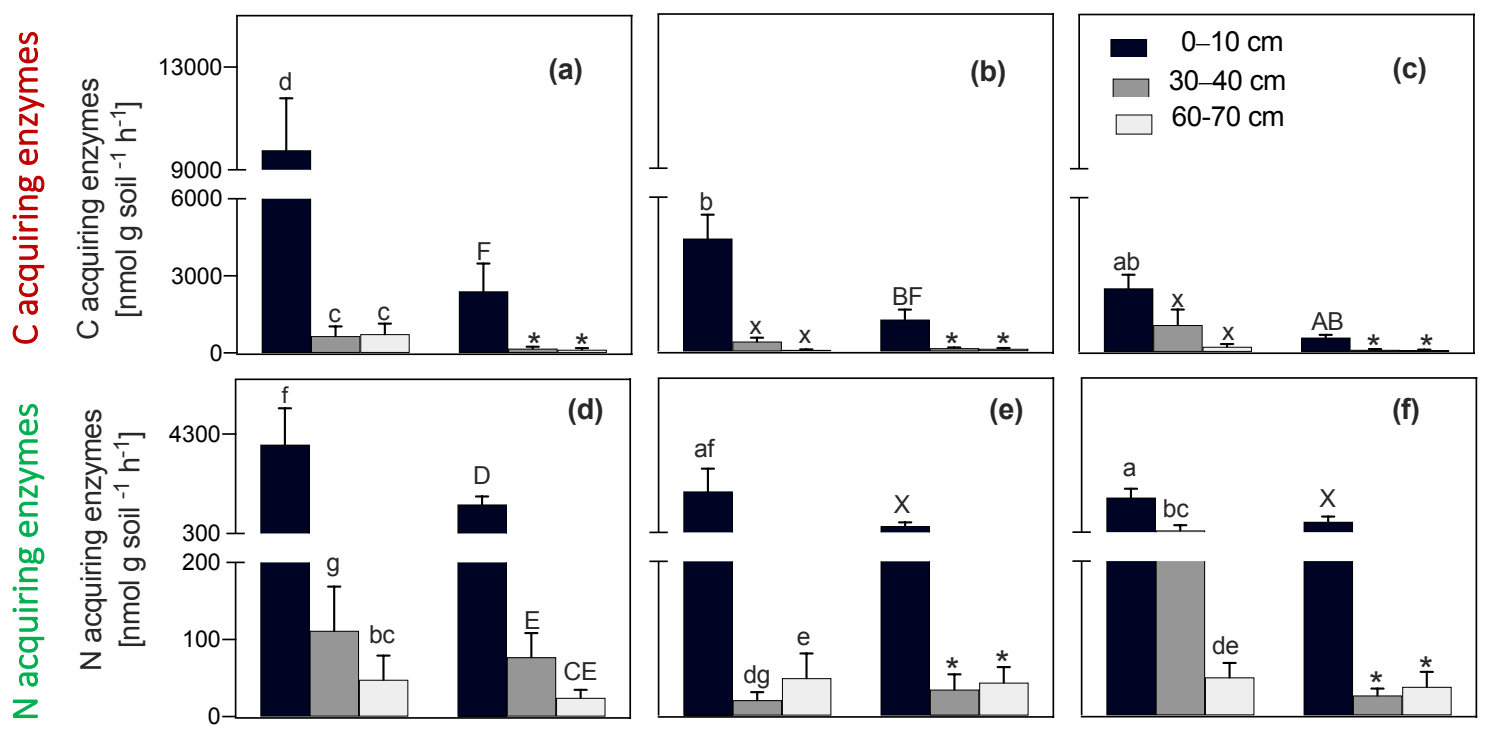

Mafic has the highest enzyme activity because of its higher DOC and microbial biomass
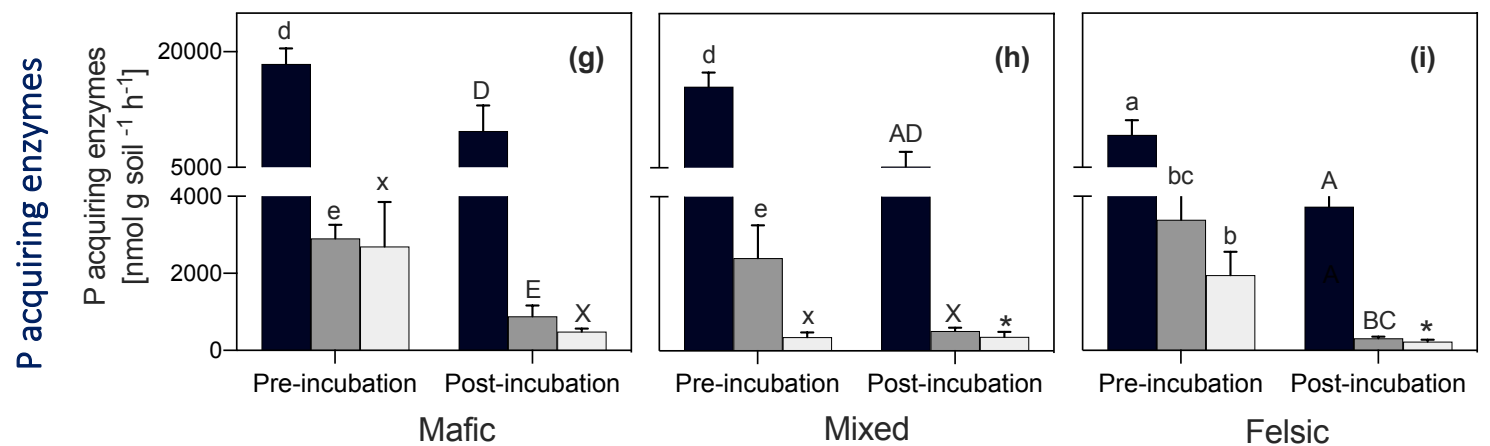

Microbial biomass and enzyme activity are markedly distinct among soils of contrasting geochemical origin due to differences in resource availability. 


\section{Are microbes in subsoils more $\mathrm{C}$ and nutrient limited that their topsoil counterparts?}
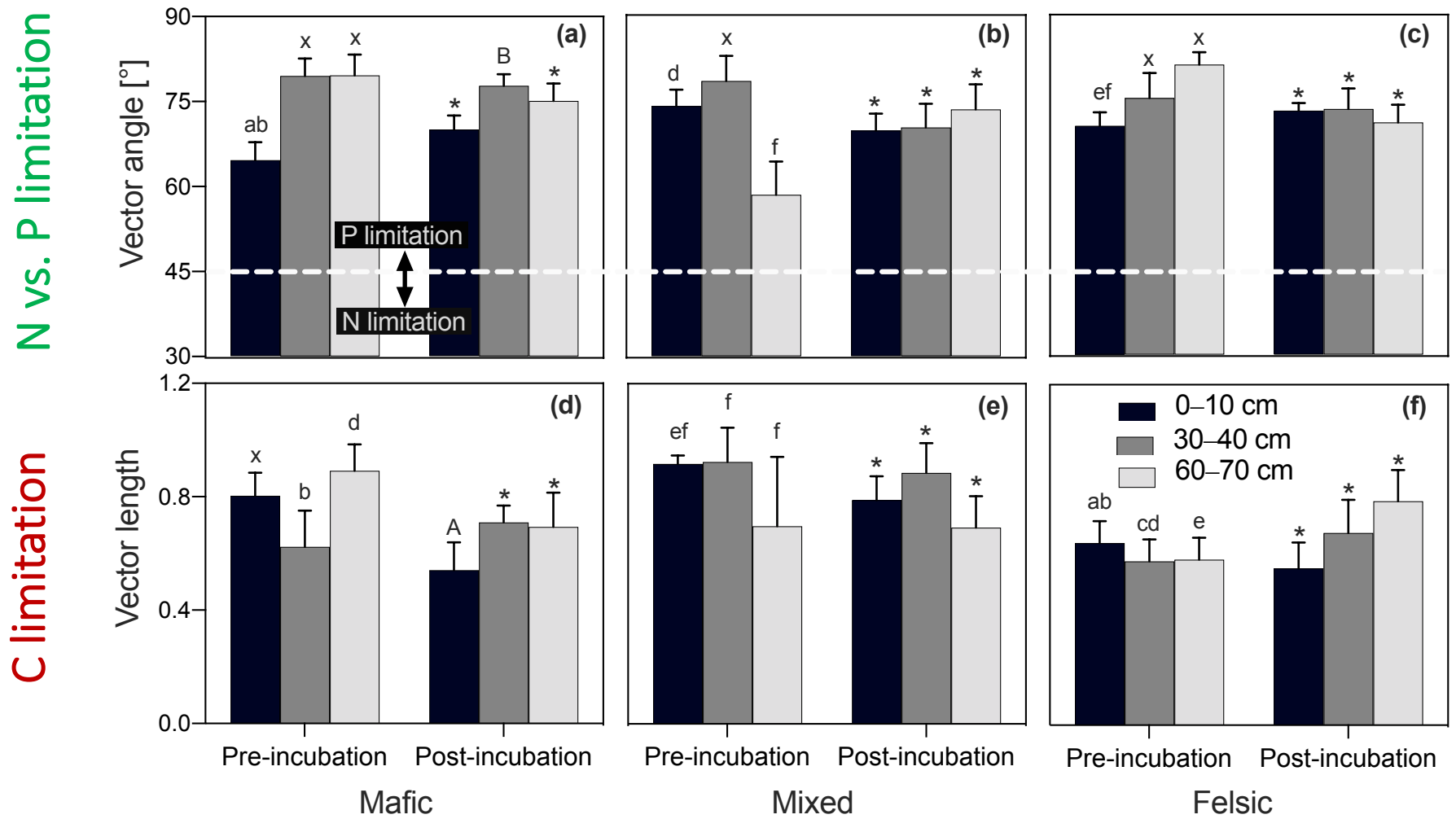

Microbes in subsoils are less C-limited than their topsoil counterparts and inversely P-limited.

Organic matter decomposition and a possible release of organic $P$ could not alleviate microbial P-limitation in a 120-day incubation experiment 


\section{How good can we predict microbial biomass, $C$, and $P$}

\section{limitation?}
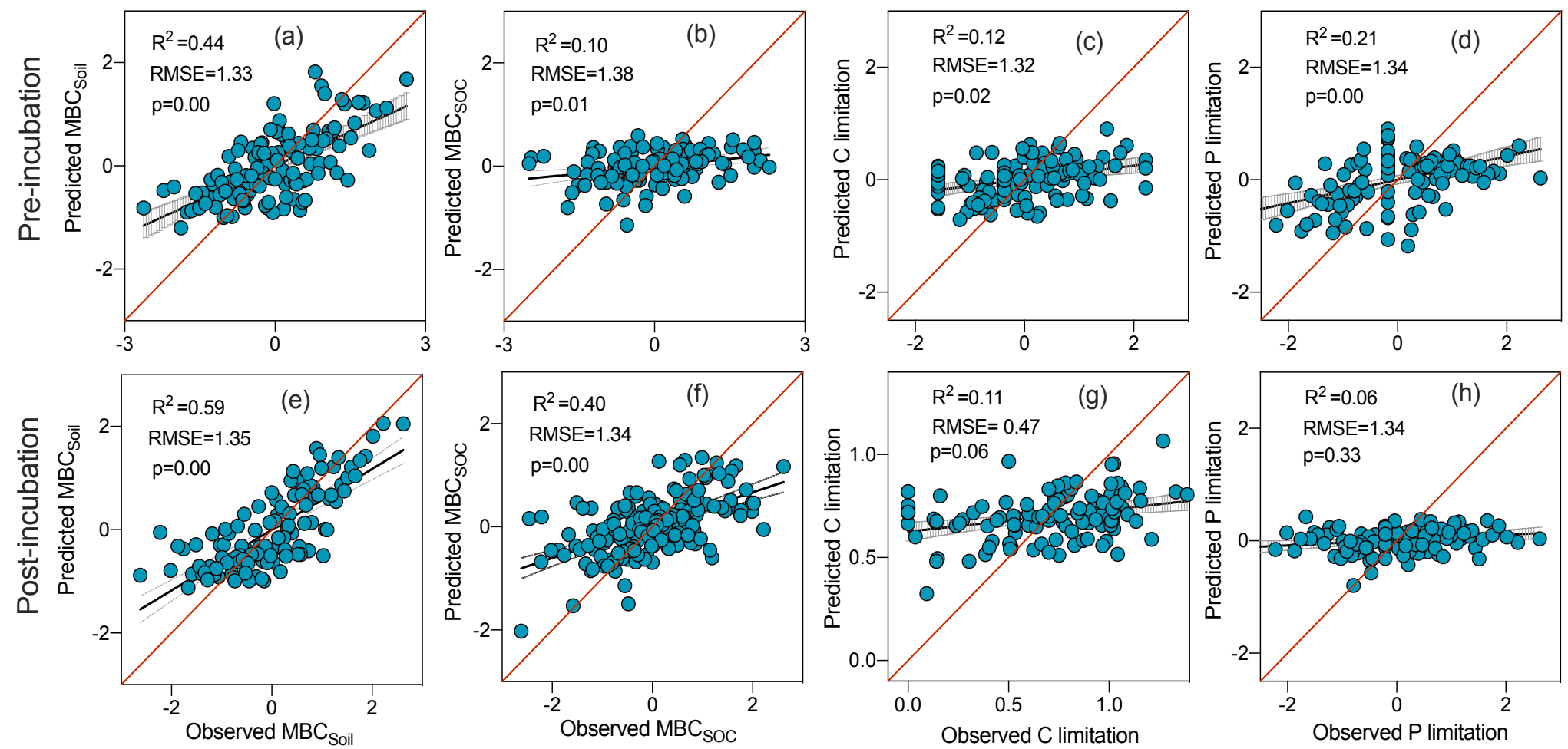

Assessed physico-chemical soil properties are important predictors for microbial biomass normalized to soil $\left(\mathrm{MBC}_{\text {soil }}\right)$ and at a lower extent microbial biomass normalized to SOC $\left(\mathrm{MBC}_{\mathrm{SOC}}\right.$, at post-incubation) but not for $\mathrm{C}$ and $\mathrm{P}$ limitations in investigated tropical soils. 


\section{What are important controls on microbial biomass, $\mathrm{C}$ and $P$ limitation ?}

\begin{tabular}{|c|c|c|c|c|c|c|c|c|}
\hline \multirow[b]{2}{*}{ Explanatory variables } & \multicolumn{4}{|c|}{ Pre-incubation } & \multicolumn{4}{|c|}{ Post-incubation } \\
\hline & $\mathrm{MBC}_{\text {Soil }}$ & $\mathrm{MBC}_{\mathrm{SOC}}$ & $\begin{array}{c}\mathrm{C} \\
\text { limitation }\end{array}$ & $\begin{array}{c}\mathrm{P} \\
\text { limitation }\end{array}$ & $\mathrm{MBC}_{\text {Soil }}$ & $\mathrm{MBC}_{\mathrm{SOC}}$ & $\begin{array}{c}\mathrm{C} \\
\text { limitation }\end{array}$ & $\begin{array}{c}\mathrm{P} \\
\text { limitation }\end{array}$ \\
\hline Organic matter & 45.6 & & & 38.9 & 49.3 & & & \\
\hline Soil depth & 35.7 & & & & 38.6 & & & \\
\hline Acidity and exchangeable cations & & & 76.0 & & & 28.5 & 43.7 & \\
\hline Substrate quality & & & & 16.5 & & 26.6 & & \\
\hline Solid phase geochemistry & & & & & & 12.7 & & \\
\hline Nitrate & & & & 22.9 & & & & \\
\hline $\mathrm{R}^{2}$ & 0.44 & 0.10 & 0.12 & 0.21 & 0.59 & 0.40 & 0.11 & 0.06 \\
\hline RMSE & 1.33 & 1.38 & 1.32 & 1.34 & 1.35 & 1.34 & 0.47 & 1.34 \\
\hline P-value & 0.00 & 0.01 & 0.02 & 0.00 & 0.00 & 0.00 & 0.06 & 0.33 \\
\hline Observations & 108 & 108 & 108 & 108 & 108 & 108 & 108 & 108 \\
\hline
\end{tabular}

Because tropical soils are deeply weathered, resource-related controls associated with organic matter abundance and quality rather than geochemical controls drive microbial biomass and $\mathrm{P}$ limitation at pre-incubation. 


\section{Take-home message}

Patterns of microbial biomass $\left(\mathrm{MBC}_{\text {soil }}\right)$ and enzyme activity in tropical soils of contrasting geochemical origin are markedly distinct due to differences in resource availability.

Because of long-lasting efficient recycling of organic matter in humid tropics, none of the investigated regions and soil depths showed signs of $\mathrm{N}$ limitation for microbial processes.

Microbes in subsoils are less C- but more P-limited compared to their topsoil counterparts

Strong controls of microbial $C$ and $P$ limitations could not be identified in this study referring to the large complexity of microbial resource acquisition.

Our findings point to the need to consider the variability in soil parent material in tropical pristine forests when assessing soil microbial processes in organic matter turnover models. 


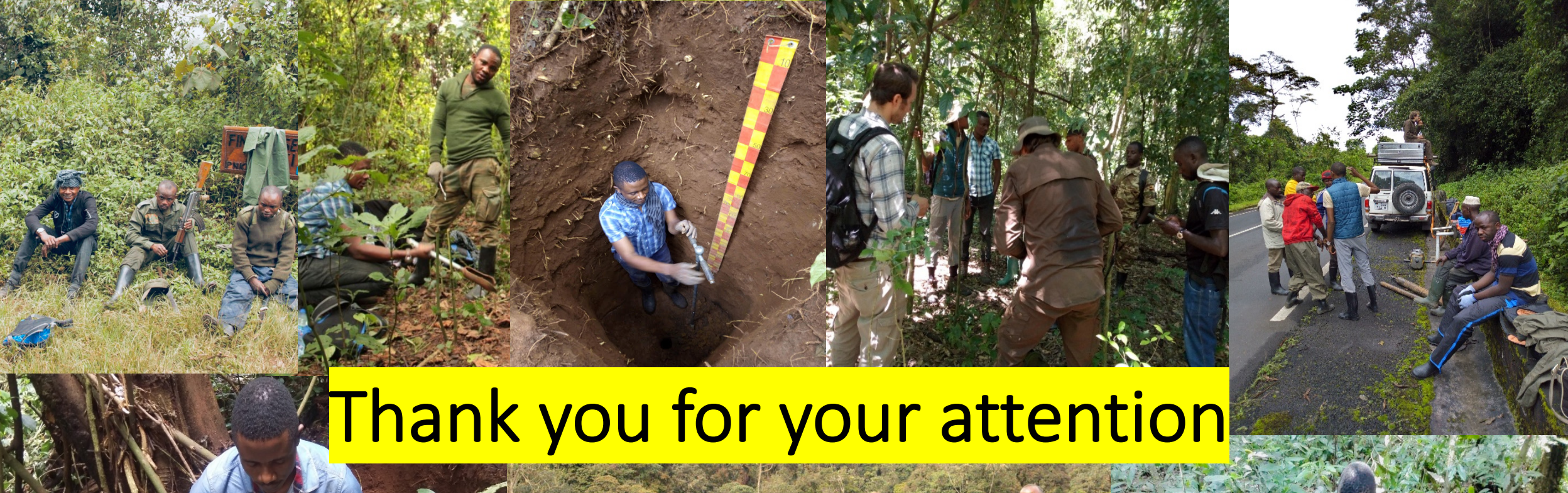

